\title{
Computational Prediction and Identification of Epstein-Barr Virus Latent Membrane Protein 2A Antigen-Specific CD8 ${ }^{+}$T-Cell Epitopes
}

\author{
Bing Wang ${ }^{1,2}$, Kun Yao ${ }^{1,3}$, Genyan Liu ${ }^{1}$, Fangyi Xie ${ }^{1}$, Feng Zhou ${ }^{1}$ and Yun Chen ${ }^{1}$
}

Epstein-Barr virus (EBV) associated nasopharyngeal carcinoma (NPC) is a high incidence tumor in Southeast Asia. Among EBV encoded proteins, latent membrane protein 2A (LMP2A) is an important antigen for $T$ cell therapy of EBV. In this study, we predicted six HLA-A2 restricted CTL candidate epitopes of LMP2A by SYFPEITHI, NetMHC and MHCPred methods combined with the polynomial method. Subsequently, biological functions of these peptides were tested by experiments in vitro. In ELISPOT assay, the positive response of the LMP2A specific CTL stimulated by three (LMP2A $A_{264-272}, L_{1} 2 A_{426-434}$ and $\left.L M P 2 A_{356-364}\right)$ of six peptides respectively showed that the numbers of spots forming cells (SFC) ranged from 55.7 to $80.6 \mathrm{SFC} / 5 \times 10^{4} \mathrm{CD8}^{+} \mathrm{T}$ cells and the responding index (RI) ranged from 5.4 to 7. These three epitope-specific CTLs could effectively kill specific HLA-A2expressing target cells. As a result, LMP2A 264-272 $_{\text {(QLSPLLGAV), LMP2A 426-434 }}$ (CLGGLLTMV) and LMP2A A56-364 $_{3}$ (FLYALALLL) were identified as LMP2A-specific $\mathrm{CD8}^{+}$T-cell epitopes. It would be useful to clarify immune response toward EBV and to develop a vaccine against EBV-correlative NPC. Cellular \& Molecular Immunology. 2009;6(2):97-103.

Key Words: Epstein-Barr virus, latent membrane protein 2A, epitope, cytotoxic T lymphocyte

\section{Introduction}

Epstein-Barr virus (EBV) belongs to the gama-herpesvirinae subfamily and is closely related to human tumors, such as Burkitt's lymphoma, nasopharyngeal carcinoma (NPC) and Hodgkin's disease (1-3). NPC is a common neoplasm in Southeast Asia, especially in southern Chinese. In the EBV-associated NPC patients, the proteins of EBV expressed on tumor cells are very limited, and only type II latency EBV antigens such as the latent EBV nuclear antigens (EBNA1) and latent membrane proteins (LMP1 and LMP2A, 2B) can be detected on NPC cells. Endogenously expressed EBNA1 is protected from processing via the conventional HLA class I processing pathway because it contains a glycine-alanine

\footnotetext{
${ }^{1}$ Department of Microbiology and Immunology, Nanjing Medical University, Nanjing 210029, China;

${ }^{2}$ Department of Clinical Laboratory, No. 81 Hospital of CPLA, Nanjing 210002, China;

${ }^{3}$ Corrspondence to: Dr. Kun Yao, Department of Microbiology and Immunology, Nanjing Medical University, Nanjing 210029, China. Tel: +8625-8686-2901, E-mail: yaokun@njmu.edu.cn
}

Received Feb 16, 2009. Accepted Apr 7, 2009.

(C2009 Chinese Society of Immunology and University of Science \& Technology of China repeat (Gar) domain that prevents degradation by the proteasome complex $(4,5)$. LMP1 is an important oncogene, and its target epitopes recognized by virus-specific cytotoxic T lymphocytes (CTLs) in NPC patients are easy to mutate (6, 7). LMP2A protein is conserved and contains HLA-restrict CTL target epitopes which can elicit strong specific CTL response $(8,9)$. So LMP2A is a potential target for immunotherapeutic approaches, although often as a subdominant target.

Computer models usefully complement experimentation in the efficient discovery of MHC-binding peptides and T-cell epitopes, and have been applied successfully to predict T-cell epitopes in infectious disease, cancer, autoimmunity and allergy. Many web-based databases and binding prediction programs are now available. In this study, SYFPEITHI $(10,11)$, NetMHC (12) and MHCPred $(13,14)$ were used for LMP2A-specific CTL epitope prediction. CTLs are the key mediators of specific immune responses against infectious diseases and cancer, and recognition of infected cells by MHC class I-restricted CTLs plays a major role in the anti-EBV immune response $(15,16)$. The epitope final identification is based on whether peptide can induce CTL response in peripheral blood mononuclear cells (PBMCs) or not. In our experiment, high-affinity candidate peptides were tested for in vitro immunogenicity with PBMCs from normal donors, and their ability to induce specific CTL cytotoxicity. 
In the present study, a combination of bioinformatics tools and in vitro assays (enzyme-linked immunospot assay (ELISPOT), intracellular cytokine staining assay (ICS) and cytotoxicity assays) was used to screen and select antigen sequences as potential LMP2A-specific $\mathrm{CD}^{+}$T-cell epitopes. Six HLA-A2-restricted peptides were selected and synthesized according to computer prediction results. Finally, only three peptides, which could induce CTL response to LMP2A in vitro, were identified as LMP2A-specific CTL epitopes.

\section{Materials and Methods}

\section{Virus and cell lines}

Recombinant vaccinia virus encoding the LMP2A gene (rVV-LMP2A) was proliferated in CV1 cells in RPMI 1640 medium supplement with 2 5\% fetal calf serums (FCS), 100 $\mathrm{U} / \mathrm{ml}$ penicillin, $0.1 \mathrm{~g} / \mathrm{L}$ streptomycin (all from GIBCO, USA) for use. T2 cell line (HLA-A2 ${ }^{+}, \mathrm{LMP}_{2} \mathrm{~A}^{-}$) was kindly provided by Prof. Yi Miao (the First Affiliated Hospital of NJMU) and was maintained in IMDM medium (GIBCO, USA) supplemented with $20 \%$ FCS. T2 cells were incubated with specific peptides $(20 \mu \mathrm{g} / \mathrm{ml})$ and $\beta_{2}$-microglobulin $(5$ $\mu \mathrm{g} / \mathrm{ml}$ ) in IMDM medium supplemented with 2 5\% FCS for two hours. After washes, peptide-loaded T2 cells were used as target cells in cytotoxicity assay. 293T-LMP2A (HLA-A2 ${ }^{+}$, $\mathrm{LMP}_{2} \mathrm{~A}^{+}$) cell line was HEK-293T cell transfected with pGEZ-LMP2A in our previous work (17) and was maintained in DMEM medium (GIBCO, USA) supplemented with $20 \%$

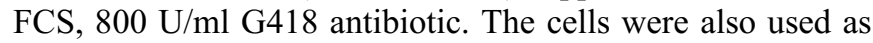
target cells in cytotoxicity assay.

\section{Computational prediction of candidate LMP2A-specific CD8 T-cell epitopes}

SYFPEITHI (http://www.uni-tuebingen.de/uni/kxi/), MHCPred (http://www.jenner.ac.uk/MHCPred/), and NetMHC (http:// www.cbs.dtu.dk/services/NetMHC-2.0/) were used for the prediction of LMP2A-specific $\mathrm{CD}^{+} \mathrm{T}$-cell epitopes.

The following criteria were used to select the candidate epitopes: a) having a higher ranking score; b) the score analyzed by polynomial method exceed threshold $(-23$ is selected); c) occurring in prediction results of above three methods no less than two times.

All peptides were synthesized by 9-fluorenylmethoxy carbonyl-based solid-phase chemistry (purity $>95 \%$ pure; KeTai Company, ShangHai, China) and dissolved in dimethylsulfoxide (DMSO). Aliquot of peptides were stored at $-80^{\circ} \mathrm{C}$.

\section{Preparation of $r V V-L M P 2 A$ transfected dendritic cells}

Dendritic cells (DCs) were induced from PBMCs of HLA-A2 positive normal donors according to previous report (18). The mature DCs were harvested and resuspended at $2 \times 10^{6}$ cells in minimal volume of media. The recombinant vaccinia virus encoding the LMP2A gene was then added to infect mature DCs at multiplicities of infection (MOI) 10. Infection was allowed to proceed for $2 \mathrm{~h}$ at $37^{\circ} \mathrm{C}$ in $5 \% \mathrm{CO}_{2}$. Then fresh complete media was added to bring the cultures to $2 \mathrm{ml}$ per well. Ten hours later, rVV-LMP2A-DCs were exposure to ultraviolet light $(25 \mathrm{~min}$ at a distance of $15 \mathrm{~cm}$ from a $30 \mathrm{~W}$ bulb) in order to deactivate vaccinia virus. In order to determine the viability of vaccinia virus infected DCs, trypan blue exclusion was used to determine viable cells. The expression of LMP2A protein in $\mathrm{rVV}-\mathrm{LMP} 2 \mathrm{~A}-\mathrm{DCs}$ was analyzed by FACS assay.

\section{Induction of LMP2A-specific CTLs by transfected DCs}

$\mathrm{CD}^{+} \mathrm{T}$ cells were enriched from PBMCs of HLA-A2 positive normal donors by positive selection using CD8 Positive Isolation Kit (Dynal, Norway). $\mathrm{CD}^{+} \mathrm{T}$ cells were co-cultured with autologous rVV-LMP2A-DCs at the ratio of 10:1 in 24-well plate in $1 \mathrm{ml}$ RPMI 1640 with $10 \%$ human $\mathrm{AB}$ serum (TBD, China) at $37^{\circ} \mathrm{C}$ in $5 \% \mathrm{CO}_{2}$. IL-2 was added at a final concentration of $20 \mathrm{U} / \mathrm{ml}$ to all wells 3 days later and every 2-3 days thereafter. Responding $\mathrm{T}$ cells were re-stimulated weekly for 2 weeks with rVV-LMP2A-DCs at same ratio. As the controls, $\mathrm{CD}^{+} \mathrm{T}$ cells were cultured with cytokine alone at the same time.

\section{IFN-y ELISPOT assay}

Mature DCs were pulsed with each LMP2A-specific peptide at $20 \mu \mathrm{g} / \mathrm{ml}$ and maintained in RPMI 1640 with $10 \%$ FCS at $37^{\circ} \mathrm{C}$ in $5 \% \quad \mathrm{CO}_{2}$ for $2 \mathrm{~h}$, followed by 2 washes with serum-free medium. The LMP2A-specific CD ${ }^{+}$T cells $(5 \times$ $10^{4} /$ well $)$ and DCs pulsed with 6 individual peptides $(5 \times$ $10 \%$ well) were added into precoated flat-bottomed 96-well (DAKEWE, China) and incubated for 24 36 h in serum-free medium lacking IL-2. Unresponsive $\mathrm{CD}^{+} \mathrm{T}$ cells against non-peptide-pulsed DCs at same ratio were served as negative control. The plate was washed and incubated with biotinylated antibody for $1 \mathrm{~h}$ at $37^{\circ} \mathrm{C}$. After washing, streptavidin-HRP was added and incubated for $1 \mathrm{~h}$ at $37^{\circ} \mathrm{C}$. The plate was washed and the spots were developed with vector AEC substrate at $20 \sim 25^{\circ} \mathrm{C}$. Spot development was stopped after $25 \mathrm{~min}$ by washing with distilled water. The plate was dried at room temperature and the spots were counted. In this study, the averages of the spots were expressed as the number of spots forming cells (SFC) per $5 \times$ $10^{4} \mathrm{CD}^{+} \mathrm{T}$ cells and responding index (RI) (19). RI = (number of $\mathrm{SFC} / 5 \times 10^{4} \mathrm{CD}^{+} \mathrm{T}$ cells with peptide - number of SFC $/ 5 \times 10^{4} \mathrm{CD}^{+} \mathrm{T}$ cells without peptide) / number of $\mathrm{SFC} / 5 \times 10^{4} \mathrm{CD}^{+} \mathrm{T}$ cells without peptide. The number of $\mathrm{SFC} / 5 \times 10^{4} \mathrm{CD}^{+} \mathrm{T}$ cells without peptide was set as background. If no spot was observed in the background, the background was approximately set up as one to make RI calculable.

\section{Induction of peptide-specific T cells}

PBMCs from EBV seropositive normal donors carrying HLA-A2 were stimulated with each peptide at a concentration of $20 \mu \mathrm{g} / \mathrm{ml}$. Next day, IL-2 was added to a final concentration of $20 \mathrm{U} / \mathrm{ml}$. The medium was changed a week later by replacing the supernatant with fresh medium containing peptide and IL-2. At day 14, living cells were enriched by Ficoll density gradient centrifugation and were 


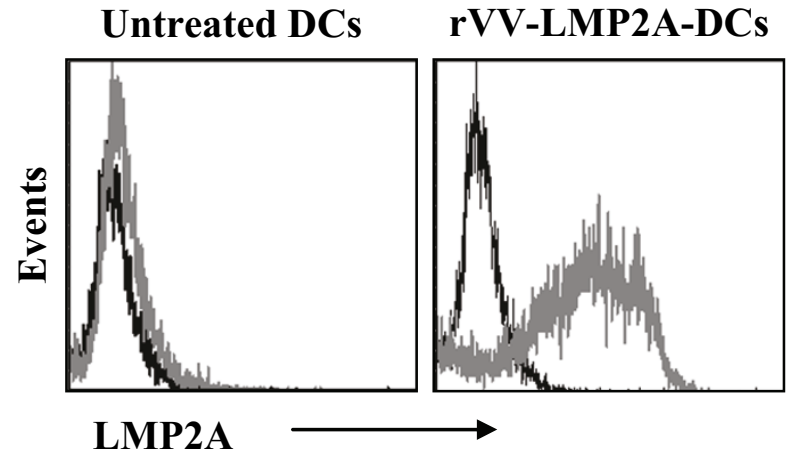

Figure 1. Expression of LMP2A in untreated and transfected DCs. Flow cytometry indicated expression of LMP2A in rVVLMP2A-DCs was $80.69 \%$ and $2.97 \%$ in untreated DCs.

used in intracellular IFN- $\gamma$ staining assay or cytotoxicity assay.

\section{Intracellular IFN- $\gamma$ staining assay}

After mature DCs had been incubated for 2 hours with each peptide, they were washed twice with RPMI 1640. These peptide-pulsed autologous DCs $\left(2 \times 10^{5}\right)$ and peptide-specific CTLs $\left(2 \times 10^{5}\right)$ were added to a 96-well U-bottomed plate, and incubated for $2 \mathrm{~h}$. The methods used for cell surface staining of CD8 and intracellular IFN- $\gamma$ staining have been described previously (20).

\section{Cytotoxicity assay}

In vitro cytolytic activity of $\mathrm{T}$ lymphocytes was measured using two-color fluorescence assay. The target cells were labeled with 3,3'-dioctadecyloxacarbocyanine $\left(\mathrm{DiOC}_{18}(3)\right)$ according to manufacturer' instruction (Invitrogen, USA). $\mathrm{DiOC}_{18}(3)$-labeled target cells were dispensed in duplicate at $2 \times 10^{4}$ cells per well into 96-well U-bottom plates. Unstained effector cells were added at various effector-totarget $(\mathrm{E}: \mathrm{T})$ ratios and mixed with the target cells. The cells
Table1. Candidate LMP2A-specific $\mathrm{CD} 8^{+}$T-cell epitopes

\begin{tabular}{|c|c|c|}
\hline Peptide & Position & "Sequences \\
\hline LMP2A $_{264}$ & $264-272$ & QLSPLLGAV \\
\hline $\mathrm{LMP}_{2} \mathrm{~A}_{300}$ & $300-308$ & ALLTLAAAL \\
\hline $\mathrm{LMP}_{2} \mathrm{~A}_{426}$ & $426-434$ & CLGGLLTMV \\
\hline $\mathrm{LMP}_{2} \mathrm{~A}_{177}$ & $177-185$ & KLLTPVTVL \\
\hline $\mathrm{LMP}_{2} \mathrm{~A}_{395}$ & $395-403$ & MLLLIVAGI \\
\hline $\mathrm{LMP}_{2} \mathrm{~A}_{356}$ & $356-364$ & FLYALALLL \\
\hline
\end{tabular}

were pelleted by centrifugation at $1,000 \times \mathrm{g}$ for $30 \mathrm{~s}$ and incubate at $37^{\circ} \mathrm{C}$ for $4 \mathrm{~h}$. Propidium iodide (PI) counterstaining solution was added into each well for the final $0.5-1$ $\mathrm{h}$ of culture. After incubation, the assay was conducted and analyzed within $24 \mathrm{~h}$ by flow cytometer.

\section{Results}

\section{T cell epitope prediction}

The frequency of HLA-A2 types in NPC patients is above $50 \%$ in the Chinese population and HLA-A*0201 type is the major subtype of HLA-A2 allele. In this study, the nonamers ( 9 aa) were chosen due to the typical length of a class I ligand comprised 9 amino acids. The sequence of the protein antigen (LMP2A) was treated respectively with YFPEITHI (http://www.uni-tuebingen.de/uni/kxi/), MHCPred (http://www. jenner.ac.uk/MHCPred/), and NetMHC (http://www.cbs.dtu. $\mathrm{dk} /$ services/NetMHC-2.0/) with MHC allele and affinity threshold. Thirty high scoring peptides were selected from the result of each prediction method (data not shown). Predicted results were then analyzed by polynomial method according to the report of Gulukota $\mathrm{K}$ et al. (21). If polynomial score exceeded a chosen threshold, the peptide was chose as the candidate epitope. The threshold is chosen as the number that gives a relatively clean separation between binders and non-binders in the training set. In the present study the threshold was -23 . The peptides which

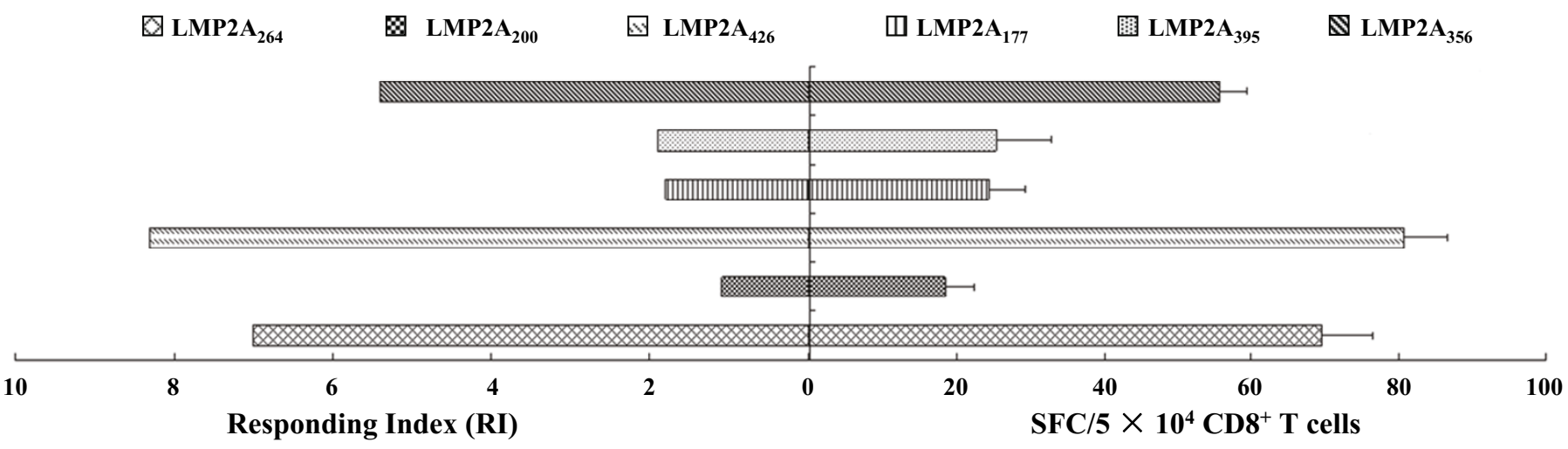

Figure 2. Recall $\mathrm{CD8}^{+}$T-cell response in IFN- $\gamma$-release ELISPOT assay. LMP2A-specific CTLs induced by rVV-LMP2A-DCs against autologous DCs pulsed with different peptides and assayed by $24 \mathrm{~h}$ ELISPOT assay. The average number of SFC/5 $\times 10^{4} \mathrm{CD} 8^{+} \mathrm{T}$ cells of triplicate cells (right) and RI (left) were calculated to represent the magnitude of cytotoxic T-cell activity. 


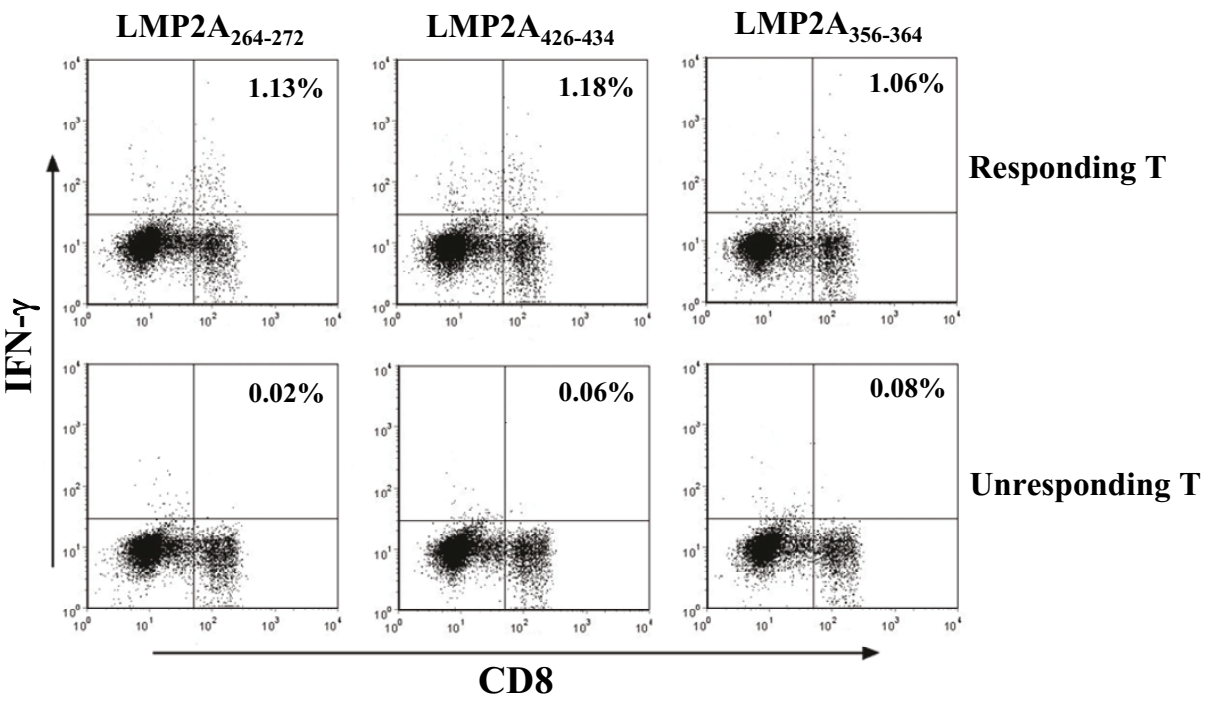

Figure 3. Frequency of $\mathrm{CDB}^{+} \mathrm{IFN}-\gamma^{+} \mathrm{T}$ cells in PBMCs after peptide stimulation. PBMCs from EBV-seropositive/HLA-A2 normal individuals were stimulated with each peptide for two weeks. The responder $\mathrm{T}$ cells were stimulated with autologous DCs pre-pulsed with each peptide. Then, intracellular-cytokine staining with flow cytometry was performed to determine the number of $\mathrm{CD} 8^{+} \mathrm{IFN}-\gamma^{+}$cells. The numbers on the upper right hand corner of each panel indicate the percentages of $\mathrm{CD}^{+}$ IFN- $\gamma^{+} \mathrm{T}$ cells in $\mathrm{CD}^{+} \mathrm{T}$ cells.

polynomial scores less than -23 were eliminated from the prediction results. At last, six candidate epitopes (shown in Table 1) were selected and synthesized for further analysis.

\section{Expression of LMP2A in transfected DCs}

Mature DCs were transfected with rVV-LMP2A at MOI 10 for $12 \mathrm{~h}$. When rVV-LMP2A-DCs were analyzed by flow cytometry, the percentage of transfected DCs expressing LMP2A was $80.69 \%$, which suggested efficient gene transfer (Figure 1)

\section{Identification of LMP2A-epitope peptides}

CTLs specific to LMP2A were obtained from purified CD8 ${ }^{+}$ $\mathrm{T}$ cells stimulated with rVV-LMP2A-DCs in vitro. After 2 week culture, the responder $\mathrm{CD}^{+} \mathrm{T}$ cells were stimulated with each peptide-pulsed DCs, and the release of IFN- $\gamma$ was detected by ELISPOT assay. The CTL activity was assessed in respect to both the magnitude of the CTL response, expressed as the average number of SFC per $5 \times 10^{4} \mathrm{CD}^{+} \mathrm{T}$ cells and the RI. The criteria to score as a positive response were spots $>20 \mathrm{SFC} / 5 \times 10^{4} \mathrm{CD}^{+} \mathrm{T}$ cells and $\mathrm{RI} \geq 2$.

In total six candidate epitopes, peptide $\mathrm{LMP}_{2} \mathrm{~A}_{264}$, LMP2 $\mathrm{A}_{426}$ and $\mathrm{LMP}_{2} \mathrm{~A}_{356}$ showed positive response. The response magnitude of these three epitopes were $69.6,80.6$ and 55.7 $\mathrm{SFC} / 5 \times 10^{4} \mathrm{CD}^{+} \mathrm{T}$ cells with RI of 7, 8.3 and 5.4 on average, respectively. While the response magnitude of other epitopes, LMP2 $\mathrm{A}_{300}, \mathrm{LMP}_{2} \mathrm{~A}_{177}$ and LMP2 $\mathrm{A}_{395}$, were 18.3, 24.3 and 25.3 SFC/5 $\times 10^{4} \mathrm{CD}^{+} \mathrm{T}$ cells with RI of 1.1 , 1.8 and 1.9 on average, respectively. The negative control (unresponsive $\mathrm{CD}^{+} \mathrm{T}$ cells against DCs without peptides) showed that number of SFC was 8.7. This implied that three peptides (LMP2 $\mathrm{A}_{264}, \mathrm{LMP} 2 \mathrm{~A}_{426}$ and $\left.\mathrm{LMP}_{2} \mathrm{~A}_{356}\right)$ might be HLA-A2-restricted CTL epitopes of LMP2A. A summary of the individual peptides that reproducibly induced response in IFN- $\gamma$ ELISPOT assay is provided in Figure 2.

Percentages of $\mathrm{CDS}^{+} \mathrm{IFN}-\gamma^{+}$T cells after peptide stimulation Responder $\mathrm{T}$ cell populations could be obtained after two rounds of in vitro stimulation. To determine whether $\mathrm{LMP} 2 \mathrm{~A}_{264}, \mathrm{LMP} 2 \mathrm{~A}_{426}$ and $\mathrm{LMP} 2 \mathrm{~A}_{356}$ can activate the specific $\mathrm{CD}^{+} \mathrm{T}$ cells in vitro, we investigated the ability of these peptide-specific $\mathrm{CD}^{+} \mathrm{T}$ cells to produce IFN- $\gamma$ after co-culture with peptide-pulsed autologous DCs by ICS assay. As shown in Figure 3, the number of antigen-specific $\mathrm{CD}^{+}$ IFN $-\gamma^{+}$double-positive cells induced by peptides was over 10 fold higher than that without stimulation. No significant response was found when co-culture with peptide-pulsed HLA-A2-negative DCs (data not shown). This result indicated that these three peptides should be considered as CTL epitopes of LMP2A protein and were presented by HLA-A2 molecules, not by other MHC alleles.

\section{In vitro CTL lysis activity by peptide stimulation}

The current flow cytometry-based cytotoxicity (FCC) assay for detecting CTL-mediated lysis is a nonradioactive alternative to the traditional ${ }^{51} \mathrm{Cr}$ release assay. Here, we conducted FCC assay to determine CTL activity. PBMCs from EBV-seropositive/HLA-A2-positive normal donor were stimulated with each peptide (LMP2A $\mathrm{A}_{264}, \mathrm{LMP}_{2} \mathrm{~A}_{426}$ and LMP2 $\mathrm{A}_{356}$ ) in medium supplemented with IL-2. After two rounds of peptide stimulation, the $\mathrm{CD} 8^{+} \mathrm{T}$ cells were purified with Dynabeads and used as effector cells in cytotoxicity assay. T2 cells loaded with each peptide derived from LMP2A protein or 293T-LMP2A cells were used as target cells. Corrected \% cytotoxicity was equal to the percentage of dead target cells in the presence of effector cells corrected for spontaneous target-cell death in the absence of effector cells. When 293T-LMP2A cells were used as targets in cytotoxicity assay they were recognized by above three peptide-specific $\mathrm{CD}^{+} \mathrm{T}$ cells, indicating that peptide $\mathrm{LMP} 2 \mathrm{~A}_{264}, \quad \mathrm{LMP} 2 \mathrm{~A}_{426}$ and $\mathrm{LMP}_{2} \mathrm{~A}_{356}$ were naturally occurring peptides and could be endogenously processed and presented by the $293 \mathrm{~T}$ cells expressing LMP2A protein. There were no differences in specific lysis activities of these three peptide-specific CTLs (Figure 4). To test whether the recognition by these three peptide-reactive CTLs was 


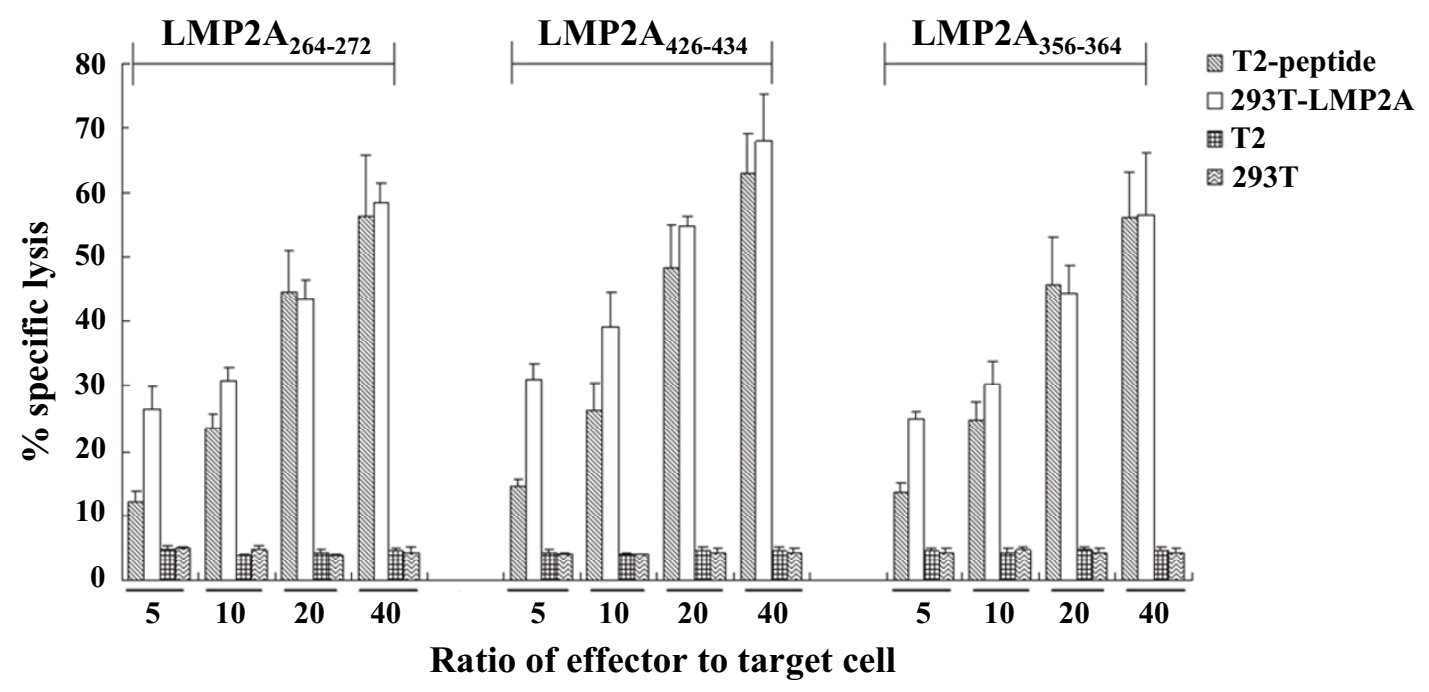

Figure 4. Killing of peptide-pulsed T2 and 293T-LMP2A cells by peptide specific CTLs. PBMCs were stimulated by peptides LMP2A 264 , LMP2 $\mathrm{A}_{426}$ and LMP2A $\mathrm{A}_{356}$, respectively, and the induced CTLs were harvested as effector cells. The corresponding peptide-pulsed T2 cells and 293T-LMP2A cells were placed in 96-well U-bottom plates at $2 \times 10^{4}$ per well and co-cultured with effector cells at the ratios of 1:5, 1:10, 1:20 and 1:40 for $4 \mathrm{~h}$. The data represent the means and standard errors of three independent experiments.

specific for the LMP2A epitope, normal 293T cells and no peptide-pulsed T2 cells were used as targets. In contrast with 293T-LMP2A cells and peptide-pulsed T2 cells, LMP2A ${ }^{-}$ $293 \mathrm{~T}$ and $\mathrm{T} 2$ cells were not recognized by peptide-reactive CTLs (Figure 4). This further confirmed that these three peptides were LMP2A-specific HLA-A2 CTL epitopes.

\section{Discussion}

$\mathrm{T}$ cell epitopes that are derived from its own cells and others can provoke the cellular immune responses after presenting to T cell. Previously, CTL epitopes were mapped using large arrays of overlapping synthetic peptides. The large number of protein sequences available for mapping is now making this method prohibitively expensive and time-consuming. At present, the synthesis of peptides prior to its MHC molecules with the possibility forecast screen out the most likely some antigen fragments, not only reduces the workload and cost, but also improves the ratio of test, which becomes the most popular approach for CTL epitope research (22). Certain differences exist in results of different CTL epitope prediction methods, due to their database source of building matrix motifs and different forms of scoring function. Here, epitope-prediction program SYFPEITHI, NetMHC and MHCPred were used to analyze the sequence of LMP2A according to their different algorithms. There were ninety peptides predicted using above three methods on the whole (30 peptides per method) and only seventeen peptides occurred no less than two times in the ninety peptides (data not shown). At last, six of the seventeen peptides were selected to be studied because other peptides were too hydrophobous to do in following tests (Table 1). Predicting a same antigen sequence with different prediction programs is a good method for CTL epitope research. It combines the advantages of above three methods and reduces the workload greatly.

Recently, there have been many attempts to use genetransfected DCs to sensitize $T$ cells to recognize target cells expressing relative antigen in research of EBV-relative malignancies (23-26). In a variety of vectors, vaccinia virus has more recently been used as a versatile eukaryotic expression vector and is important in tumor gene transfecting. Indeed, several studies have shown that vaccinia gene has successfully transfered into human DCs and results in induction of a T-cell response against tumor $(27,28)$. Our results showed that the expression of LMP2A in transfection DCs reached a high level of $80.69 \%$, which indicated efficient gene transfection. In some studies, EBV transformed B lymphoblastoid cell lines (LCLs) have been used to induce EBV-specific CTLs, but LCL against immunodominant EBV antigens such as the EBNA3A, 3B, and 3C that are not expressed in EBV-associated NPC (29). Here, the responder LMP2A-specific $\mathrm{CD}^{+} \mathrm{T}$ cells were induced by $\mathrm{rVV}$ LMP2A-DCs instead of LCLs. The result showed that it is a useful method to stimulate $\mathrm{T}$ cells in vitro by dendritic cells infected with antigen-carrying vaccinia or adenoviral vectors.

In the study, we predicted six candidate peptides by computer prediction results. But not all peptides were effective LMP2A-specific CTL epitopes. It needs to be confirmed through functional experiments in vitro because prediction precision is not yet completely satisfactory and some peptides, although good binders, are never processed properly for presentation. In order to identify the CTL epitope specific for LMP2A, we generated CTLs specific to whole LMP2A protein by method of stimulation with rVV-LMP2A-DCs (see Materials and Methods). When the CTLs co-cultured with each peptide pulsed-DCs, IFN- $\gamma$ 
release was detected by ELISPOT. As a result, only specific spots were formed in the wells where stimulated with LMP2A $_{264}$ (QLSPLLGAV), LMP2A A $_{426}$ (CLGGLLTMV) and LMP2A $_{356}$ (FLYALALLL) pulsed-DCs respectively. The assay proved that LMP2A protein could be endogenously cleaved in three nonamers (QLSPLLGAV, CLGGLLTMV, FLYALALLL) at least and processed by autologous DCs to present MHC-peptide complex on DC surface. Since LMP2A constitutes potentially the major target antigen for immunotherapy of NPC, many researchers aimed to identify T-cell epitopes located in this protein and defined some T-cell epitopes $(30,31)$, such as peptide LMP2 $\mathrm{A}_{426}$ and $\mathrm{LMP}_{2} \mathrm{~A}_{356}$, which were LMP2A specific epitopes. We also defined them in our study. However, to our knowledge, peptide LMP2 $\mathrm{A}_{264}$ was the first LMP2A-specific $\mathrm{CD} 8^{+} \mathrm{T}$ cell epitope identified in Chinese population.

Peptide-specific CTLs could be harvested by two methods: a) induction of CTLs with APCs (such as DCs) pulsed with peptide, $b$ ) induction of CTLs from PBMCs with peptide stimulation directly. Responding $\mathrm{T}$ cells were re-stimulated weekly for at least two weeks in both methods. We adopted the latter method for its convenience and availability. Then the characterization of peptide-specific CTLs was analyzed in vitro by ICS and cytotoxicity assays. All of three peptide-specific CTLs induced from EBVseropositive/HLA-A2 positive normal donor were able to recognize the peptide-pulsed autologous DCs in ICS assay, while the CTLs could not recognize peptide-pulsed HLA-A2negative DCs. In our previous work, the 293T-LMP2A cell line was proved to express LMP2A protein (17). The peptide-specific $\mathrm{CD}^{+} \mathrm{T}$ cells effectively killed HLA-A2 ${ }^{+}$ LMP2A $^{+} 293$ T cells but not the normal 293 T cells (HLA-A2 ${ }^{+}$ LMP2A $\mathrm{A}^{-}$). These data confirmed that the peptides LMP2A 264 , $\mathrm{LMP}_{2} \mathrm{~A}_{426}$, and LMP2 $\mathrm{A}_{356}$ were specific LMP2A epitopes and its presentation to the cell surface in the context HLA-A2 molecules.

Taken together, six candidate peptides of LMP2A were predicted by computer and three peptides $\left(\mathrm{LMP}_{2} \mathrm{~A}_{264}\right.$, LMP2 $_{426}$ and $\mathrm{LMP}_{2} \mathrm{~A}_{356}$ ) were identified as HLA-A2 restricted LMP2A-CTL-epitopes with experiments in vitro. Furthermore, LMP2A 264 (QLSPLLGAV) is a novel LMP2Aspecific-epitope that was the first be demonstrated in this study. It provides good candidates to design the peptide-based immunotherapeutic strategies for the treatment of EBV-seropositive NPC patients.

\section{Acknowledgements}

We thank Prof. M.H.Ng and Bojian Zheng of the University of Hong Kong for kindly providing the rVV-LMP2A. This work was supported by the National Nature Science Foundation of China (No.30571715).

\section{References}

1. Niedobitek G. Epstein-Barr virus infection in the pathogenesis of nasopharyngeal carcinoma. Mol Pathol. 2000;53:248-254.
2. Dolcetti R, Masucci MG. Epstein-Barr virus: induction and control of cell transformation. J Cell Physiol. 2003;196:207218.

3. Young LS, Rowe M. Epstein-Barr virus, lymphomas and Hodgkin's disease. Semin Cancer Biol. 1992;3:273-284.

4. Levitskaya J, Coram M, Levitsky V, et al. Inhibition of antigen processing by the internal repeat region of the Epstein-Barr virus nuclear antigen-1. Nature. 1995;375:685-688.

5. Levitskaya J, Sharipo A, Leonchiks A, Ciechanover A, Masucci MG. Inhibition of ubiquitin/proteasome-dependent protein degradation by the Gly-Ala repeat domain of the Epstein-Barr virus nuclear antigen 1. Proc Natl Acad Sci U S A. 1997;94: 12616-12621.

6. Pai S, Khanna R. Role of LMP1 in immune control of EBV infection. Semin Cancer Biol. 2001;11:455-460.

7. Floettmann JE, Rowe M. Epstein-Barr virus latent membrane protein-1 (LMP1) C-terminus activation region 2 (CTAR2) maps to the far C-terminus and requires oligomerisation for NF- $\kappa B$ activation. Oncogene. 1997;15:1851-1858.

8. Straathof KC, Leen AM, Buza EL, et al. Characterization of latent membrane protein 2 specificity in CTL lines from patients with EBV-positive nasopharyngeal carcinoma and lymphoma. J Immunol. 2005; 175:4137-4147.

9. Lalonde A, Avila-Carino J, Caruso M, de Campos-Lima PO. Rescue of the immunotherapeutic potential of a novel $\mathrm{T}$ cell epitope in the Epstein-Barr virus latent membrane protein 2. Virology. 2007;361:253-262.

10. Rammensee H, Bachmann J, Emmerich NP, Bachor OA, Stevanovic S. SYFPEITHI: database for MHC ligands and peptide motifs. Immunogenetics. 1999;50:213-219.

11. Schuler MM, Nastke MD, Stevanovikc S. SYFPEITHI: database for searching and T-cell epitope prediction. Methods Mol Biol. 2007;409:75-93.

12. Lundegaard C, Lamberth K, Harndahl M, Buus S, Lund O, Nielsen M. NetMHC-3.0: accurate web accessible predictions of human, mouse and monkey MHC class I affinities for peptides of length 8-11. Nucleic Acids Res. 2008;36:W509-512.

13. Guan P, Doytchinova IA, Zygouri C, Flower DR. MHCPred: A server for quantitative prediction of peptide-MHC binding. Nucleic Acids Res. 2003;31:3621-3624.

14. Guan P, Hattotuwagama CK, Doytchinova IA, Flower DR. MHCPred 2.0: an updated quantitative T-cell epitope prediction server. Appl Bioinformatics. 2006;5:55-61.

15. Haque T, Wilkie GM, Jones MM, et al. Allogeneic cytotoxic T-cell therapy for EBV-positive posttransplantation lymphoproliferative disease: results of a phase 2 multicenter clinical trial. Blood. 2007;110:1123-1131.

16. Demachi-Okamura A, Ito Y, Akatsuka Y, et al. Epstein-Barr virus (EBV) latent membrane protein-1-specific cytotoxic $\mathrm{T}$ lymphocytes targeting EBV-carrying natural killer cell malignancies. Eur J Immunol. 2006;36:593-602.

17. Chen Y, Yao K, Wang B, Qing J, Liu G. Potent dendritic cell vaccine loaded with latent membrane protein $2 \mathrm{~A}$ (LMP2A). Cell Mol Immunol. 2008;5:365-372.

18. Berger TG, Feuerstein B, Strasser E, et al. Large-scale generation of mature monocyte-derived dendritic cells for clinical application in cell factories. J Immunol Methods. 2002; 268:131-140.

19. Zhang HG, Pang XW, Shang XY, Xing Q, Chen WF. Functional supertype of HLA-A2 in the presentation of Flu matrix p58-66 to induce $\mathrm{CD}^{+}$T-cell response in a Northern Chinese population. Tissue Antigens. 2003;62:285-295.

20. Kitano M, Kobayashi N, Kawashima Y, et al. Identification and characterization of HLA-B*5401-restricted HIV-1-Nef and 
Pol-specific CTL epitopes. Microbes Infect. 2008;10:764-772.

21. Gulukota K, Sidney J, Sette A, DeLisi C. Two complementary methods for predicting peptides binding major histocompatibility complex molecules. J Mol Biol. 1997;267:12581267.

22. Martin W, Sbai H, De Groot AS. Bioinformatics tools for identifying class I-restricted epitopes. Methods. 2003;29:289298.

23. Pan Y, Zhang J, Zhou L, Zuo J, Zeng Y. In vitro anti-tumor immune response induced by dendritic cells transfected with EBV-LMP2 recombinant adenovirus. Biochem Biophys Res Commun. 2006;347:551-557.

24. Gahn B, Siller-Lopez F, Pirooz AD, et al. Adenoviral gene transfer into dendritic cells efficiently amplifies the immune response to LMP2A antigen: a potential treatment strategy for Epstein-Barr virus--positive Hodgkin's lymphoma. Int J Cancer. 2001;93:706-713.

25. Redchenko IV, Rickinson AB. Accessing Epstein-Barr virus-specific T-cell memory with peptide-loaded dendritic cells. J Virol. 1999;73:334-342.

26. Bollard CM, Straathof KC, Huls MH, et al. The generation and characterization of LMP2-specific CTLs for use as adoptive transfer from patients with relapsed EBV-positive Hodgkin disease. J Immunother. 2004;27:317-327.

27. Bontkes HJ, Ruizendaal JJ, Schreurs MW, Kramer D, Meijer CJ, Hooijberg E. Antigen gene transfer to human plasmacytoid dendritic cells using recombinant adenovirus and vaccinia virus vectors. Cell Oncol. 2005;27:175-182.

28. Nagorsen D, Panelli M, Dudley ME, Finkelstein SE, Rosenberg SA, Marincola FM. Biased epitope selection by recombinant vaccinia-virus (rVV)-infected mature or immature dendritic cells. Gene Ther. 2003;10:1754-1765.

29. Herr W, Ranieri E, Olson W, Zarour H, Gesualdo L, Storkus WJ. Mature dendritic cells pulsed with freeze-thaw cell lysates define an effective in vitro vaccine designed to elicit EBV-specific $\mathrm{CD}^{+}$and $\mathrm{CD} 8^{+} \mathrm{T}$ lymphocyte responses. Blood. 2000;96:1857-1864.

30. Lautscham G, Haigh T, Mayrhofer S, et al. Identification of a TAP-independent, immunoproteasome-dependent CD8+ T-cell epitope in Epstein-Barr virus latent membrane protein 2. J Virol. 2003;77:2757-2761.

31. Lee SP, Thomas WA, Murray RJ, et al. HLA A2.1-restricted cytotoxic $\mathrm{T}$ cells recognizing a range of Epstein-Barr virus isolates through a defined epitope in latent membrane protein LMP2. J Virol. 1993;67:7428-7435. 